\section{PIANOFORTE TOUCH.}

WHEN the editor of Popular Mechanics submitted a list of modern inventions to a referendum to select the "seven principal wonders of the modern world," the piano-player and player-piano were conspicuous by their absence from the long collection, although they possess quite as many features of scientific interest as many of the inventions actually submitted. These mechanisms have, moreover, failed, for some not very obvious reason, to form the subject of discussion in scientific and technical journals where frequent mention is made of such proprietary inventions as motor cars, gramophones, kinematographs and the like. Yet a number of subjects for scientific discussion may be suggested in connection with piano-players. The psychologist, for example, will notice that after a very little experience the performer does not consciousiy move his regulator to play faster or slower; but he unconsciously plays the notes at the exact instants that he thinks of them quite as much as if he were striking the keys with his fingers.

The attempt to compare pneumatic playing with finger playing in the matter of "touch" lands us in a very difficult problem of dynamical acoustics which has not received so much attention as it deserves from physicists. We are told that the piano-player cannot reproduce the clear singing pianissimo of the finger pianist, that there is a certain element wanting which only the human fingers can supply. What is this element? A piano-player can be played as softly or as loud as is desired, it allows full use of the pedals, and a slight jerk of the time lever enables the performer to "linger on a note" as well as an ordinary pianist. But still, we are told, the "touch" is not the same, and if a few notes are played from the music roll and then played with fingers, a certain difference in the quality of the tone often appears noticeable.

Now the quality of a note, apart from its actual loudness, depends on the relative intensity of the fundamental tone and its several harmonics, and we are thus led to inquire into the question how far the harmonics of a pianoforte note are capable of being intensified or reduced independently of the fundamental tone.

It is obvious that great differences in quality are produced by the use of the loud pedal, and the old-fashioned soft pedal which shifted the hammer off one of the strings and caused a softer part of the hammer to strike the others had an equal effect; moreover, the singing qualities and delicate harmonics are quite destroyed by shutting up a piano and covering it with ornaments. But even when other conditions are kept constant, differences are noticeable according to whether the same note is struck with a sharp blow or a heary pressure, and we are thus led to the important question: Are the intensities of the fundamental tone and its harmonics functions of one variable only, or are they functions of two or more variables?
Now upon this point I find that a yreat disagreement of opinion exists. Many piano-make:s in this country hold to the single-variable hypothesis on the ground that when the hammer is striking the strings it is disconnected from the keys; if this were not the case the note would be "blocked." On this hypothesis the striking velocity of the hammer constitutes the single independent variable. The single-variable theory is not inconsistent with the possibility that the character of a note may vary according to its loudness; this only requires that the intensities of the various components shall be different functions of the same variable instead of being multiples of the same function.

Other people will tell us that if it were possible to produce differences in the quality of a pianoforte note, they would be too small to be appreciable.

In Germany, on the other hand, I am informed that great importance is attached by teachers of the pianoforte to differences in the manner of applying pressure to the keys. During the small interval of time that the key is being depressed, this pressure is an arbitrary function of the time, or, if preferred, of the displacement, the form of the function depending on the action of the fingers and in particular on their elasticity, and the German method distinctly assumes the existence of a relationship between the form of this function and the quality of the note sounded.

Neither Helmholtz's nor Kaufmann's theories afford an explanation of the "two-variable" hypothesis. I believe other papers have been published dealing with this question, both experimentally and theoretically, and I hope the present article will be the means of eliciting information on the subject. It is evident that such investigations have not become widely known among physicists. From the point of view of applied mathematics, the difficulty of the problem consists in finding fundamental assumptions which lead to the desired conclusions, and are at the same time consistent with the structural conditions as they exist in the pianoforte. Two possible explanations suggest themselves :-

I. Although the hammer is at a slight distance from the wires in its position of equilibrium, it may still be acted on by some impressed force while touching the string, owing to the elasticity of the connections.

2. The stem of the hammer is flexible and capable of independent vibration, so that the circumstances of the impact may depend on the bending set up in projecting the hammer.

I am now investigating the equations of motion based on these two alternative assumptions, but the problem is a very difficult one, and it seems desirable to obtain further experimental evidence before any final conclusions can be reached.

For some time past I have obtained results with a piano-player which exhibit conspicuous discrepancies from what one would expect on the single-variable theory, and a good deal of care has been exercised in ascertaining that these effects 
are not due to mere imagination. My experiments have been so far directed towards the question as to how far differences of dynamical touch can be made to produce effects that can be noticed by an ear not specially trained to observe them. The apparatus used in these experiments consists of a horizontal lever fixed in front of a piano-player of the usual standard type; the short arm of this lever is connected by a wire passing over pulleys, or by some other connection, with the small auxiliary bellows of the player, and acts directly on it, the usual spring being removed. The lever carries a sliding weight by which the collapsing tension of the bellows can be regulated. When the bellows collapses it closes a kind of throttle valve in the mechanism, thus cutting the air off

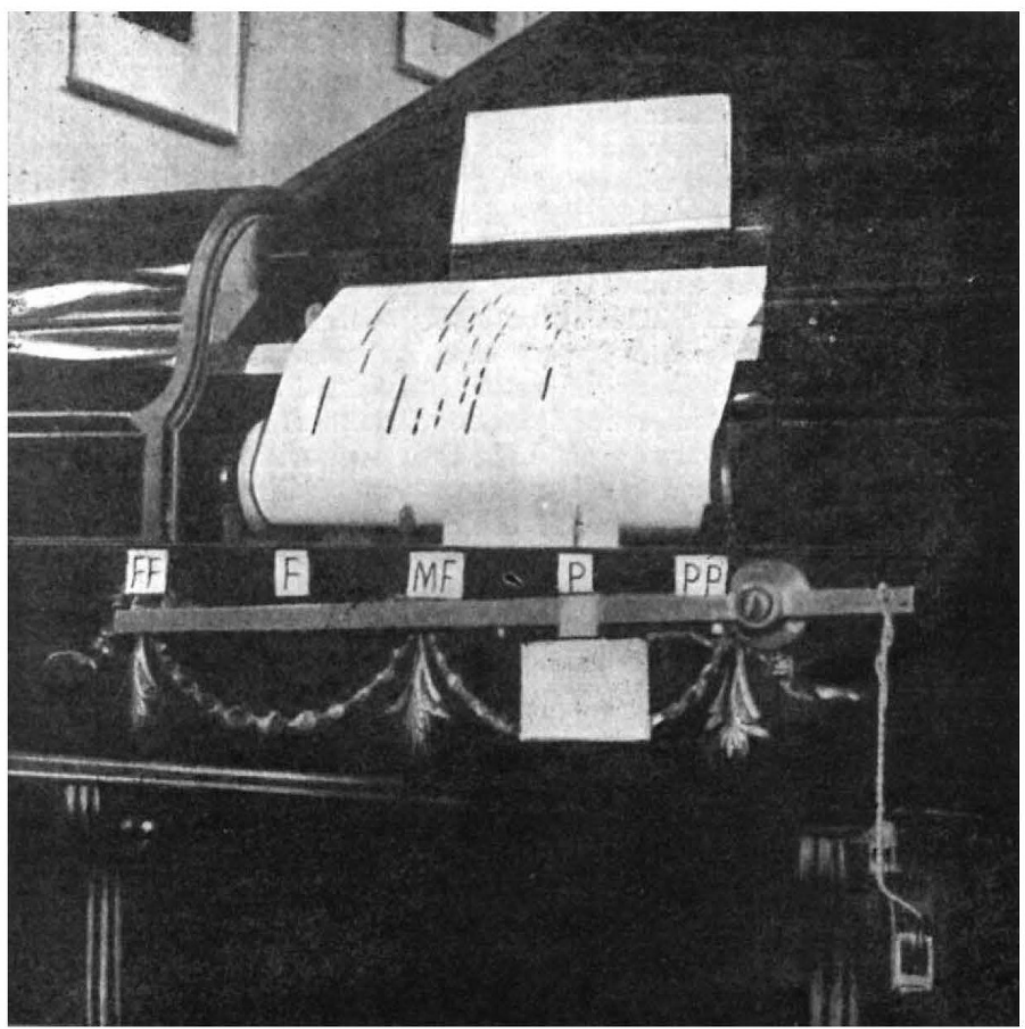

Fig. 1.-Apparatus (provisionally protected) for controlling the touch of a piano-plaser.

of chords is not necessarily inconsistent with the single-variable theory, since the hammers are of different mass in different parts of the scale, and therefore undergo different accelerations when the same variable force is applied to them. This dynamical differentiation is more satisfactory than the popular mechanical arrangement for controlling the two halves of the keyboard, as it involves no hard and fast dividing line.

In a passage involving chords it is impossible to separate the effects due to differences between the notes of a chord from any possible differences between the harmonics of the notes, and therefore it is necessary to choose a solo passage in order to effect a decisive test. I have shown such tests to a good many people; a few notice either no differences or only very slight differences. On the other hand, it is very surprising to find how many people notice conspicuous differences, and those who are most successful in detecting them are often people with no ear for music and no previous musical training. In most cases I ask them to describe what they observe without previously preparing them. It is thus evident that the dynamical effects dependent on these differences of touch, so far from being negligible, must have a marked influence on the impressions formed by a large proportion of both the musical and unmusical people who attend a first-class pianoforte recital.

Something more than merely sliding a weight is necessary to approximate to the rendering of a good pianist, who can vary his action on the keys from one note to the other. To effect the same result the lever must be controlled by hand as well, being pressed or jerked from above or below practically in an unlimited variety of ways. An almost infinitesimal touch of the finger will often cause a particular note to ring out brilliantly. In the commercial

and producing an action similar to that effected by a short sharp impulse applied to the pianoforte keys. By increasing the load, by shifting the weight towards the end FF, a heavier sustained pressure is produced.

When the same passage is played first with the weight at PP and then with it at FF, a noticeable difference is observed. The loudness can be made about the same in both cases by suitably altering the pressure on the pedals, but in the former position the result is a brilliant "metallic" effect in which the treble notes stand out conspicuously, while in the latter position soft, mellow tones are produced in which the bass notes predominate.

The differentiation between bass and treble parts player the performer has to depend mainly for these effects on his feet. Now not only are feet much less sensitive than fingers, but the effects are so modified by the elasticity of the various springs that these latter have a predominating influence in governing the touch, and a considerable effort on the part of the performer often produces only a slight difference in the result.

A remarkable instance of how a trifling cause may greatly modify pianoforte tones was shown in a recent demonstration at the Physical Society, when the effects were observed to be rather loud and harsh. In this case a copper wire was used for the connection between the lever and bellows instead of one of steel. On trying the copper con- 
nection at home the effects were identical with those shown at the Imperial College.

In this country little attention is paid to pianoforte touch, owing, probably, to the use of boxedup pianos covered with jangling ornaments, when sufficient volume of sound has to be obtained by violently hammering the keys and bobbing down the pedals through harmonics and discords. Moreover, the average pianoforte pupil has too much to do with learning execution to trouble about "touch," and very few professionals produce variations in the quality of their notes at all approaching the possible maximum. It is not surprising, therefore, to find widespread belief in the single-variable theory. At the same time, I do not consider it possible to overlook the numerous results of independent observation which are inconsistent with that theory.

It is much to be hoped that the increasing popularity of the player-piano will lead to increased interest in the more scientific aspects of piano-playing.

The explanation of the acoustical effects produced by the modern pianoforte is probably a dynamical problem of considerable complexity, depending on a number of causes, many of which have hitherto been neglected. It is important that not only should attention be directed to any investigations bearing on the matter which have commonly been overlooked, but that further experiments should be carried on with the object of better localising the apparent discrepancy which exists between theory and observation.

G. H. BRYAN.

\section{AGRICULTURAL EDUCATION.}

FOR many years past technical education of a more or less efficient kind has been provided for the majority of our leading industries, but for some reason or other our greatest industry of all, and that on which indirectly all the others depend, has been left with scarcely any provision at all. It may be that this is due to the fact that agriculture is the nurseling of one Government Department and education of another, and that under our rigid red-tape-bound system, agriculture has no dealings with education. It gives peculiar pleasure, therefore, to note that this system shows signs of amendment, and one of the firstfruits of reform is seen in a memorandum recently issued by the Board of Agriculture and Fisheries to local authorities in England and Wales offering grants from the newly-established development fund towards the furtherance of technical instruction in agriculture and horticulture.

The grants promised are intended to aid (1) in the establishment of advisory councils to be set up in each county or group of counties for the purpose of reviewing, governing, and co-ordinating or initiating schemes for providing higher agricultural education and educational experiments in connection therewith; $(2)$ in the provision and maintenance of buildings and lands for farm schools and farm institutes, at which young agriculturists and others whose daily business is connected with the land may obtain scientific and practical instruction in the technicalities of their art. At each of these schools and institutes it is intended that a highly efficient staff shall be maintained to give short courses of instruction in summer and winter suited to the requirements of the district, also to conduct experimental and research work, and to which agriculturists can apply for advice in cases of difficulty. The grants for farm schools and institutes may be partly annual where new or additional work is being undertaken.

Somewhat stringent conditions are laid down for the administration of the grants to prevent their being applied to the relief of the ratepayers in those districts where such work has already been begun, but that these districts may not be discouraged, the proportion of the grant to the actual expenditure may vary from 50 to 75 per cent., having regard to the financial burden hitherto undertaken by each local authority in this direction.

A covering letter directs attention to the leading provisions of the memorandum, and gives, amongst other things, the Board's ideas with regard to the appointment and duties of a responsible official or organiser in each county or division. The success or otherwise of the scheme will depend very largely upon whether the right man is or is not found for this important post, and as suitable men cannot at the present time be very plentiful, the authorities will be well advised not to insist too rigidly on the paper qualifications of the candidates, but to judge each on his merits, past performances, and experience in agricultural education and organisation.

The scheme outlined contains the germ of an excellent system, but its success or failure will depend largely upon the skill and tact with which it is developed. When the curricula and atmosphere of our rural elementary and secondary schools have been reformed so as to complete the scheme, and the inherent prejudices of the farming community have been overcome, we may hope for a good return for the money spent, but we must not look for abundance of fruit before the tree has had time to take root and expand its branches. Progress will doubtless be slow, and much patience, skill, and trouble will have to be expended before a crop may be looked for.

\section{William Aldridge.}

\section{NOTES.}

AT: the meeting of the Linnean Society on May $I$ Prof. Hermann von Vöchting was elected a foreign member, and the president announced that it had been decided to award the Linnean medal to Prof. Adolf Engler.

THE council of the Manchester Literary and Philosophical Society has nominated Sir Thomas H. Holland, K.C.I.E., F.R.S., to represent the society at the twelfth International Congress of Geology, to be held in Toronto in August next.

A MESSAGE from the Wellington correspondent of The Times on May I says :--Miss Procter's mission

NO. $227 \mathrm{I}$, VOL. 9I] 